\title{
The standard written algorithm for addition: Whether, when and how to teach it
}

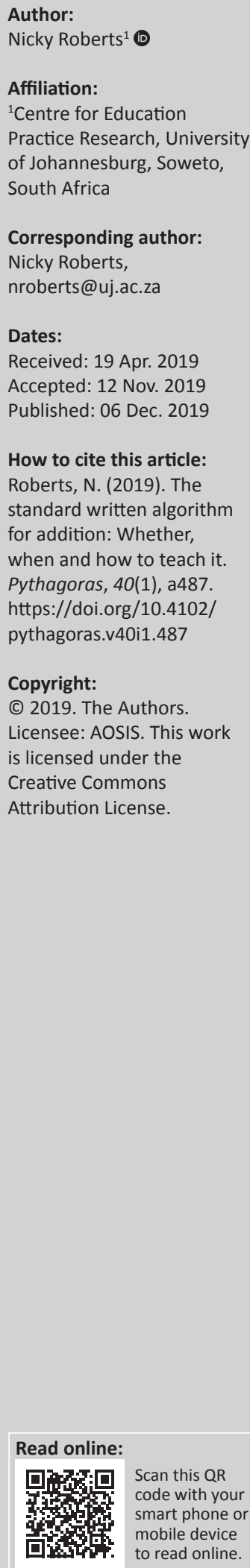

This article reflects critically on the guidance offered to South African teachers in two canonical texts: the Curriculum and Assessment Policy Statements (CAPS) and Mathematics teaching and learning framework for South Africa: Teaching mathematics for understanding (TMU). I make explicit my philosophical orientation, and how 'teaching mathematics for (relational) understanding' is evident in both documents. Distinctions are drawn between strategy, representation and procedure, and the progression towards efficient calculation strategies is emphasised (neither of which is clear in the CAPS). The suggestion made in the TMU framework is that teachers can shift from bundling concrete manipulatives for multi-digit numbers to the standard written algorithm in Grades R-3, which contradicts both the CAPS and insights gleaned from mathematics education literature and two learning programmes that have shown positive results at large scale. In particular, the justifications for delaying teacher introduction of 'break up both numbers' strategies are discussed. Further, when the 'break up both numbers' strategy is used, alternatives to the standard written algorithm which have been found to be more accessible to learners - expanded notation, write all totals, and new groups below - are offered. Ways of using empty number lines and 'drawing numbers' to show the 5-wise and 10-wise structure are suggested. These alternative representations for breaking up both numbers are expected to be accessible to teachers for whom the standard written algorithm is a familiar calculation strategy.

Keywords: multi-digit; column addition; standard written algorithm; Foundation Phase; South Africa; primary school; mathematics; curriculum.

\section{Introduction}

Any mathematics education community (researchers, teacher educators, government officials, subject advisors, materials developers, instructional leaders, teachers, trade union officials, etc.) ought to seek out, and provide, theoretically sound guidance on how to approach the teaching of particular topics in mathematics. Ernest (2014) refers to policy in mathematics education as the 'teaching sequence for the subject as planned and experienced by the learner' and distinguishes four aspects which are commonly the focus of mathematics education policy debates:

1. the aims, goals, and overall philosophy of the curriculum;

2. the planned mathematical content and its sequencing, as in a syllabus;

3. the pedagogy employed by teachers, and

4. the assessment system. (p. 480)

The four aspects are clearly related to each other, and ought to cohere. Within such mathematics communities it is expected and appropriate that there are debates, discussion and contestation over what mathematics is, why it has value, and how it ought to be taught. Absence of disagreement - with various positions and their underlying rationales being openly and hotly debated - ought to be cause for concern. Despite the inevitable contestation, there is simultaneously a need for 'sufficient consensus' to steer the way mathematics is approached in schools.

In South Africa the legislated policy framework provides this 'sufficient consensus' and is articulated through a national curriculum policy. Such curriculum policy is expected to be subject to revisions over time while maintaining sufficient stability to avoid disruptions to a large, yet fragile, public schooling system. Currently, South Africans are guided by a national curriculum and assessment policy statement (CAPS) for mathematics which gives specific learning outcomes for Grade R - Grade 12 (Department of Basic Education [DBE], 2012a, 2012b). More recently further guidance has been offered with the publication of a Mathematics Teaching and Learning Framework for South Africa: Teaching Mathematics for Understanding (DBE, 2018), hereafter 
referred to as the 'TMU framework'. Importantly, the TMU framework does not replace the CAPS (DBE, 2018, pp. 2, 3, $10,12)$. Its purpose is articulated as follows:

This (TMU) Framework is not a new curriculum and does not replace the existing curriculum. Instead it supports the implementation of the current curriculum through introducing a model to help teachers to change the way in which they teach. The Framework model and the supporting exemplars are provided to offer guidance to teachers that will enable them to transform their teaching. This transformation should lead to teaching for understanding, so that learning for understanding will take place in all mathematics classrooms in South Africa. (DBE, 2018, p. 10, emphasis in original)

As such at the heart of the TMU framework is an intention to support a transformation in how mathematics is taught in South African schools. From the Minister of Education's perspective, the TMU framework is a contribution to the urgent need to pay particular attention to the development of a new curriculum for initial teacher education, induction and continuing professional development' (DBE, 2018, p. 3). As such it may be viewed as an attempt to forge greater coherence between the remit of the Department of Higher Education and Training (responsible for initial teacher education), and that of the various branches within the DBE (responsible for national policy relating to assessment, curriculum and teacher development) and the various provincial Departments of Education (responsible for the implementation of national policy at provincial level).

It is worthwhile reflecting on the nature of the transformation envisaged for 'teaching mathematics with understanding'. In this regard I draw on Hiebert (1999), who summarises traditional teaching of primary arithmetic as follows:

Most characteristic of traditional mathematics teaching is the emphasis on teaching procedures, especially computation procedures. Little attention is given to helping students develop conceptual ideas, or even to connecting the procedures they are learning with the concepts that show why they work. (p. 12)

In contrast, drawing across numerous successful studies in the teaching of primary arithmetic, Hiebert (1999) identifies their common characteristics, asserting that the hoped for and envisaged teaching of mathematics should build directly on learners' entry knowledge and skills, provide opportunities for both invention and practice, focus on the analysis of (multiple) methods, and ask students to provide explanations.

Notwithstanding its articulated focus on Ernest's (2014) 'aspect 3: pedagogy', the TMU framework identifies implications that go beyond pedagogy. It proposes potential changes to curriculum, assessment, learning and teaching support materials and information and communication technology (DBE, 2018, pp. 76-79). By way of concrete example, the DBE in collaboration with the National Education Collaborative Trust has developed a detailed learning programme (comprising learner workbooks and detailed lessons plans) as one interpretation of what is advocated for by the TMU framework. This learning programme is currently being field tested, and its outcomes are expected to inform a planned process for strengthening the CAPS (Meeting with DBE curriculum branch, June 4, 2019).

Given the potential influence of the TMU framework, it is therefore imperative that both it and the CAPS are reflected upon critically. Their similarities and differences should be noted and motivated for. This article focuses on one particular aspect of guidance offered to teacher educators and mathematics teachers in the TMU framework which is a clear departure from that which is offered in CAPS: the 'standard written algorithm (SWA)' for addition and subtraction, as illustrated in Figure 1.

Following Fischer et al. (2019) I use the phrase 'standard written algorithm (SWA)' which may also be referred to as the 'traditional vertical algorithm' or 'condensed column method', among others. The CAPS refer to 'adding and subtracting in columns' while the TMU framework refers to a 'column method for recording numeric work'.

In South Africa, this particular aspect of the mathematics education policy debate relates to how to teach 'context free calculations for addition and subtraction' in the Foundation Phase (DBE, 2012a). The clarification notes in CAPS delay the teaching of the SWA to Grade 5 in the Intermediate Phase. In contrast, the TMU framework advocates for inclusion of the SWA for addition much earlier - in the Foundation Phase (which spans Grades R to 3).

\section{Methodology Research questions}

The research questions being reflected on for this article are theoretical. I therefore first make clear my philosophical orientation towards mathematics which underlies my response to two research questions: First, what does research offer in relation to whether, when and how to approach teaching vertical algorithms? And second, how do the teacher guidelines on addition calculation strategies in the CAPS accord with, and differ from, those offered in the TMU framework? These questions are answered in order to reflect critically on the CAPS and TMU framework in order to inform the expected process of strengthening CAPS.

\section{Methods and analysis}

In pondering these questions I drew on mathematics education literature pertaining to learning-teaching trajectories into number and multi-digit addition to frame the article and inform my document analysis.

$\begin{array}{r}3^{1} 4 \\ +\quad 47 \\ \hline 81 \\ \hline\end{array}$

FIGURE 1: An illustration of the standard written algorithm (SWA) for addition. 
I conducted a detailed content analysis of the two DBE documents: the CAPS and the TMU framework. I 'identified visual-quantitative learning supports and written-numeric aspects' (Fuson \& Li, 2009) of addition procedures given in the two canonical South African texts. For both documents my primary focus was on the Foundation Phase (Grades R-3) and in the case of CAPS this extended to the Intermediate Phase (Grades 4-6). I limited my attention to 'methods, techniques or strategies' relating to formal written methods for addition calculations. I examined every page and took notes of multi-digit addition examples. Where the same method was repeated in a document I did not include it again, as my intention was not to examine frequency of occurrence. I then compared the examples offered in the two South African documents to each other, and to the research evidence presented from the literature.

On receiving feedback from the peer review process for this article, I revisited both of the canonical texts again and engaged further with the literature. In addition I met with the government officials responsible for mathematics curriculum. This meeting provided further details about the purpose of the TMU framework and its status in relation to existing policy. Following this further research and personal engagements I realised the need to, firstly, clarify the conceptual distinctions I made with regard to my use of the terms 'procedure', 'strategy' and 'representation', and, secondly, to include a learning programme (considering textbooks, learner books and teacher lessons plans) perspective. Although the theoretical findings from academic research were of value, I felt I had been remiss in not considering how a couple of large-scale mathematics improvement interventions approached multi-digit addition.

In order to include some engagement with guidance relating to multi-digit addition as offered to teachers (rather than researchers), I purposively selected two well-known early grade mathematics learning programmes: Everyday Mathematics from the USA (see Bell et al., 2015) and Mathematics Recovery / Count Me in Too which originated in Australia and is now used in several countries (Wright, Martland, Stafford, \& Stanger, 2006). I selected these two programmes as they are well documented, have been developed by universities over decades, were widely used, and have been empirically researched to show positive results at a large scale in primary schools mathematics. See Ward (2009) and Riordan and Noyce (2001) for Everyday Mathematics, and Wright et al. (2006) for Mathematics Recovery. These are also programmes which accord with the orientation to mathematics as teaching for relational, rather than instrumental, understanding (Skemp, 1987), adopted and made explicit in this article.

\section{Clarifying the use of the terms 'strategy', 'procedure' and 'representation'}

There is some conceptual fuzziness with regard to distinguishing a range of terms: procedure, method, model, strategy, algorithm, representation and technique. The various interpretations of, and contestations relating to, each of these terms is beyond the scope of this article. As such, I simply make explicit the ways in which these terms are used in the South African CAPS and TMU framework, and then how I use 'strategy', 'procedure' and 'representation' to analyse the documents, in this article.

The CAPS explain that 'in the early grades children should be exposed to mathematical experiences that give them many opportunities 'to do, talk and record their mathematical thinking' (DBE, 2012a, p. 10). This distinguishes the act of doing mathematics, from orally communicating about mathematics (to self and others), and from recording mathematics. The CAPS uses the term 'techniques' which it presents as a synonym for 'methods or strategies' offering a list of techniques appropriate for each grade in the Foundation Phase (DBE, 2012a, p. 21).

To me, the CAPS does not adequately distinguish a strategy (way of thinking), from a representation (how such thinking is recorded), from a procedure (a generalised step-by-step rule or process on how to create a particular representation to depict a particular strategy). Drawing on Kilpatrick, Swafford and Findell's (2001) definition of mathematical proficiency, the TMU framework deliberately distinguishes strategies from procedures:

Procedures: The processes through which mathematics is done. Much of school mathematics involves procedural working which learners need to be able to perform fluently.

Strategies: The approaches used to do mathematical procedures and perform mathematical calculations. Learners should be able to use a variety of strategies and to devise their own strategies when they solve mathematical problems and do mathematical calculations. (DBE, 2018, p. 7)

I view a procedure as a specific step-by-step process which can always be followed to implement a particular strategy for a calculation (and hence, over time, procedures can be performed fluently). Procedures may be followed mentally (as internal representations) or communicated using words (mathematics talk to self or others) or by drawings, number symbols, operations, gestures and so on (and so making use of external representations).

The notion of a 'representation' as used in mathematics education becomes important here as this draws attention to the particular way in which a procedure is recorded:

As most commonly interpreted in education, mathematical
representations are visible or tangible productions - such as
diagrams, number lines, graphs, arrangements of concrete objects
or manipulatives, physical models, mathematical expressions,
formulas and equations, or depictions on the screen of a computer
or calculator - that encode, stand for, or embody mathematical
ideas or relationships... To call something a representation thus
includes reference to some meaning or signification it is taken to
have. (Goldin, 2014, p. 409)

Thomas (2014) argues that algorithms are a type of mathematical procedure: 'the idea of an algorithm is closely related to what, 
in mathematics education terms, are often called procedures, since these may be accomplished using algorithms' (p. 37).

I view a strategy as a mental process - a particular way of thinking or approach to a calculation. As such strategies are internally represented to self, and then a strategy may be externally represented to others in numerous ways. Importantly, there is not a one-to-one mapping between a strategy and a representation. A particular strategy may be represented in multiple ways. For example to calculate $34+7=\ldots$ a child may use a 'count on in ones strategy', and represent this in many ways: orally, using mathematics drawings or on a number line, as shown in Figure 2. How to make use of a particular representation to communicate a strategy can be broken down into a generalised step-by-step process which is referred to as a procedure.

The standard written algorithm for addition, as shown in Figure 1, records the steps of a procedure, with a representation using digits arranged in base-ten place-value columns, where a strategy of 'break up both numbers using place value' is adopted for addition calculations. The breakup-both-numbers strategy can be represented in other ways too, and the SWA is not the only representation to support this strategy.

\section{Philosophical orientation}

When critiquing canonical texts or policy documents, the critical commentary ought to make clear its philosophical positioning. There are underlying philosophies of what mathematics is, which mathematics is worth knowing, and how one might expect children to learn. These approaches

\begin{tabular}{|c|c|c|}
\hline Representation & $\begin{array}{l}\text { Learner communication } \\
\text { of representation }\end{array}$ & Procedure \\
\hline Oral and gestures & $\begin{array}{l}34 \text { (in my head) } \\
\text { Counts on in ones } \\
\text { (using the small number } \\
\text { sequence): } 35,36,37,38 \text {. } \\
39,40,41 \text { Keeps track of } 7 \\
\text { counts using fingers. }\end{array}$ & $\begin{array}{l}\text { Unit-wise 'counting on', using } \\
\text { fingers } \\
\text { Start with the first number: } 34 \\
\text { (in my head) Count on in ones } \\
\text { (using the small number } \\
\text { sequence): } 35,36,37,38,39 \text {, } \\
40,41 \\
\text { Keep track of second number } \\
\text { (7 counts) on fingers. }\end{array}$ \\
\hline $\begin{array}{l}\text { Mathematical } \\
\text { drawing }\end{array}$ & $\begin{array}{l}34 \quad \bullet \bullet \bullet \bullet \bullet \bullet \bullet ~ \\
34+7=41\end{array}$ & $\begin{array}{l}\text { Unit-wise 'counting on', using } \\
\text { tallies } \\
\text { Start with first number: } 34 \text {. } \\
34 \text { (in my head) } \\
\text { Count on in ones (using the } \\
\text { small number sequence): } 35 \text {, } \\
36,37,38,39,40,41 \\
\text { Keep track of second number } \\
\text { (7 counts) using marks in ones }\end{array}$ \\
\hline Number line & $\bigcap_{3435363738394041}$ & $\begin{array}{l}\text { Unit-wise 'counting on', using } \\
\text { hops on a number line } \\
\text { Draw a line } \\
\text { Start at with the first number: } \\
34 . \\
\text { Hop in ones (small number } \\
\text { sequence). } \\
\text { Keep track of the second } \\
\text { number ( } 7 \text { hops) to reach } 41 \text {. }\end{array}$ \\
\hline
\end{tabular}

FIGURE 2: Exemplar representations and related procedures for a 'count on in ones' strategy for $34+7$. are based on values and beliefs and necessarily differ by country, by national curriculum and by individual. It is therefore worthwhile to make explicit my philosophical orientation to mathematics learning.

I take mathematics learning to involve learning ways of thinking. This approach has been succinctly defined by Carpenter, Franke and Levi (2003) as follows:

Learning mathematics involves learning ways of thinking. It involves learning powerful mathematical ideas rather than a collection of disconnected procedures for carrying out calculations. But it also entails learning to generate those ideas, how to express them using words and symbols, and how to justify to oneself and others that those ideas are true. (Carpenter et al., 2003, p. 1)

My view on mathematics learning is compatible with how mathematics is defined in the South African CAPS:

Mathematics is a language that makes use of symbols and notations for describing numerical, geometric and graphical relationships. It is a human activity that involves observing, representing and investigating patterns and qualitative relationships in physical and social phenomena and between mathematical objects themselves. It helps to develop mental processes that enhance logical and critical thinking, accuracy and problem-solving that will contribute to decision-making. (DBE, 2012a, p. 8)

Notice the slight shift in emphasis in these definitions. While Carpenter et al. (2003) attend to mathematics learning - which is described as a way of thinking - the CAPS attends to the mathematics itself, acknowledging it as part of human activity which helps to develop mental processes (ways of thinking).

It is worth emphasising that I take mathematics learning to involve learning powerful ideas rather than a collection of disconnected procedures for carrying out calculations (Carpenter et al., 2003). My position is informed by the fact that the nature of mathematics (and what is worth learning) has changed as a result of near ubiquitous and cheap access to calculating devices (such as calculators, computers and mobile phones). This change in access to technology for calculations has implications for mathematics pedagogy:

In society today, there is general acceptance that 'drill and practice' of taught routines will not prepare children for life in technological society and that teaching approaches need to focus on the links that demonstrate the logical structure underlying numbers and number operations. Rather than being shown how to do written calculations, children are to be encouraged to work mentally to observe patterns to predict results and to talk about the connections that can be made. (Anghileri, 2000, p. 2)

This view has driven much of the mathematics reform agenda, as evident in the NCTM Standards in the USA (see, for example, Kilpatrick, Martin, \& Schifter, 2003). Skemp (1987) made an important contribution to this debate by distinguishing instrumental understanding ('rules without reasons') from relational understanding ('knowing what to do and why'). The former involves 'memorising which 
problems a method works for and which not, and also learning a different method for each new class of problems' (Skemp, 1987, p. 159), and is about developing 'proficiency in a number of mathematical techniques' (p. 156). While methods (without understanding) may be potentially useful in the short term, in the longer term this is quite detrimental, and generally involves conceiving of mathematics as a set of isolated, unrelated set of techniques which should be memorised (Star, 2014, p. 305).

The TMU framework emphasises teaching mathematics with 'understanding', which could refer to either relational or instrumental understanding. However, the TMU framework refers to a purposeful move to conceptual understanding rather than memorisation of procedures in this extract:

Although the four key dimensions (conceptual understanding, mathematics procedures, strategic competence, and reasoning) are interdependent and should be properly linked to optimise effective teaching and learning of mathematics, it could be argued that more emphasis should be placed on conceptual understanding since this is the metaphorical foundation on which all other dimensions build. The emphasis on conceptual understanding is a purposeful move to address the common teaching and learning practice which is characterised by memorisation of mathematical procedures with little understanding of how they were derived, why they work and when they are relevant. (DBE, 2018, p. 13)

Further evidence of support for relational rather than instrumental understanding appears in other parts of the TMU framework too:

Modern societies and economies are in a constant state of flux. It is no longer sufficient for learners only to learn how to reproduce the steps in the calculations that they are shown by teachers. (p. 15)

If children learn procedures without understanding, their knowledge may be limited to meaningless routines. (p. 16)

Mathematics is not simply a collection of isolated procedures and facts; it consists of a web of interconnected concepts and relationships. If learners are taught mathematics as a series of disconnected procedures that need to be learnt off by heart, they are likely to experience mathematics as meaningless. It will also mean that they have more to memorise which deprives them of the opportunity to develop higher order thinking skills. (p. 18)

These quotes reveal that the TMU framework hopes to contribute to a shift away from reproduction of steps to calculations shown by teachers and meaningless routines, towards mathematics as a web of interconnected concepts and relationships.

The attempt to shift away from learning mathematics as instrumental understanding is not new in South Africa. Spending significant time on mastering taught written routines for quick and accurate calculation in school mathematics has been questioned for over three decades. Olivier (1992) argued that 'when the emphasis is on promoting understanding of number and algorithmic thinking, and not on speed and accuracy, the standard contracted and refined algorithms should be abandoned' (p. 217). This forms part of global debates on whether to include written algorithms at all in mathematics curricula. Kamii and Dominick (1997) made a strong appeal that the time has come to stop teaching the algorithms and, instead, encourage children to make the mental relationships necessary to build number sense' (p. 60).

I do not share Kamii and Dominick's (1997) view that teaching written algorithms is irrelevant and should not be part of primary curricula. In this regard I follow Kilpatrick et al.'s (2001) conception of having five strands of mathematical proficiency: conceptual understanding, procedural fluency, strategic competence, adaptive reasoning and a productive disposition. This framing recognises that procedural fluency is a valuable strand of mathematical proficiency. My reasons for adopting this orientation are varied.

Firstly, I concur with Olivier (1992) that promoting procedural fluency in the use of the standard contracted and refined algorithms (SWA) should be abandoned. Rather, Olivier advocates that the learning of calculation should promote understanding of number, algorithmic thinking and cultural transmission. I also think there is intrinsic value in studying a variety of algorithms and socio-cultural mathematical artefacts developed in particular contexts for particular periods of time. This value has been strengthened with the future-looking focus on coding and the 'algorithmics' which underlies artificial intelligence.

Secondly, having a reliable 'go-to' algorithm for enacting a particular calculation strategy (strategic competence) frees up time and attention for other important mathematical processes such as adaptive reasoning, proof and explanation. I emphasise that I do not consider the 'go-to' algorithm to imply that the same strategy and representation must be used by all children in a class. I expect that children have their own go-to algorithm which is appropriately efficient for their grade level.

Thirdly, if we consider teachers to be products of their own mathematical learning experiences (see Roberts, 2017), then the mathematical procedures that teachers have already automated is a resource which they bring with them into their own (re-)learning of mathematics. Offering expanded written methods using columns (such as the 'write all totals' algorithm discussed below) would build directly on South African teachers' existing knowledge and skills about column algorithms.

\section{Discussion}

\section{What does research offer in relation to when, and how, to approach teaching SWA?}

I identified what, in my view, are fundamental insights about the developmental progression of young children's sense of numbers from counting to efficient calculation strategies. 
Each key insight is briefly discussed in turn, drawing on the literature informing it. I first consider the various strong justifications to delay the introduction of the SWA as a taught way of recording the 'break-up both numbers' strategy. I then discuss the important considerations on how to use columns methods (of which SWA is a very condensed form) when a 'break up both numbers' strategy is used.

Insight 1: The strategies that children use for single-digit addition and subtraction are well documented.

Researching young children's thinking in a project referred to as Cognitively Guided Instruction, Carpenter and Fennema (1999) identified three calculation strategies commonly used for solving additive relation problems and also considered these in a hierarchy of mathematical sophistication: direct modelling, counting, and calculating. Direct modelling refers to the use of concrete apparatus such as manipulatives (like counters, or fingers) to enact a situation that closely resembles the problem situation. By counting, Carpenter and Fennema refer to strategies that make use of unit counting to calculate. For 'counting in ones', calculation strategies vary in levels of sophistication:

- Count all.

- Count on (from the first number, and then from the larger number).

- Count up to reach a target.

In this case counting strategies refer to unit counting, rather than counting in groups (such as twos, fives or tens). Calculating refers to more sophisticated strategies which do not use unit counting. Calculating strategies may use:

- Counting in groups or counting on in groups (using the medium and large number sequences of counting in tens and hundreds, from any number).

- Building on known facts (often knowledge of bonds of five and ten to 'fill up or make tens' and doubling or halving).

- The relationship between the numbers in the calculation for solving.

All of these single-digit calculation strategies are also used for multi-digit calculations. At first learners need to 'fill up the ten' for calculations resulting in a solution that is more than ten. Later the same strategies are used to fill up any multiple of ten. A 'make a ten' (or multiple of ten) strategy is included in 'building on known facts'. Knowledge of the bonds of ten (the whole number pairs which sum to 10: 1 and 9, 2 and 8, 3 and 7 , etc.) is therefore central, as is knowledge of breaking down single digit numbers. Using 'the relationship between numbers' includes solving a subtraction calculation using an unknown addend. So $9-7=\ldots$, is solved as $7+\ldots=9$. Here any addition or subtraction fact is seen as belonging to a family of equivalent number sentences. In line with this trajectory, Fuson and Li (2009) provide levels for the counting pathway into number making use of: count all, count on, 'make a ten' and doubles as key methods.
It is important to notice that these trajectories do not expand on the shift into formal written calculations. Their focus is primarily on the early grades $(\mathrm{R}-3)$.

Insight 2: Children's shift from counting in ones to efficient calculation strategies takes years

Efficient calculation strategies - which include use of formal written algorithms - take more than 3 or 4 years of formal schooling. From the Netherlands, Van den Heuvel-Panhuizen (2008) provides a 'learning-teaching trajectory' of young children's likely progression for whole number calculation, but this trajectory makes specific reference to the expected progression towards more structured representations of number and additive relations. Structured representations make use of quick-5, quick-10 and quick-100 arrangements, which refer to drawings or arrangements in which the objects or markings are spatially arranged so that it is quick and easy to identify groups of 5 or 10 or 100 . Importantly such a learning-teaching trajectory is not seen as strictly linear but includes discontinuities, individual differences in learning processes and so each level has a 'certain bandwidth' (Van den Heuvel-Panhuizen, 2008, p. 13).

Working within this Dutch tradition, Treffers and Buys (2008) provide attainment targets which are viewed as 'benchmarks', or reference points against which the development of children can be assessed. The teaching-learning trajectory in Table 1 outlines 10 broad levels of development from counting to calculating, adapted from Treffers (2008a), Treffers (2008b) and Treffers and Buys (2008) in Van den Heuvel-Panhuizen (2008).

The Treffers and Buys (2008) framework (Table 1) is a coarsegrained delineation of development levels which spans 7 years. When focusing on two-digit addition, levels 6-10 in the Treffers and and Buys (2008) framework are relevant. Building on this tradition, Kühne, Lombard and Moodley (2013) developed a 'learning pathway for number' for the South African context which reduced the 10 levels to 4 stages spanning from prior to schooling to Grade 5. In its summary form, the 'learning pathway for number'

TABLE 1: Treffers and Buys's trajectory from counting to calculating.

\begin{tabular}{|cll}
\hline Level & Descriptor & Approximate age \\
\hline 1 & Learning to count & Approximately age 2 \\
\hline 2 & Context-bound counting-and-calculating & - \\
\hline 3 & Object-bound counting-and-calculating & - \\
\hline 4 & Towards pure counting-and-calculating via symbolisation & - \\
\hline 5 & $\begin{array}{l}\text { Calculation by counting where necessary by counting } \\
\text { materials }\end{array}$ & - \\
\hline 6 & From counting to structuring & - \\
\hline 7 & $\begin{array}{l}\text { Calculation by structuring with the help of suitable } \\
\text { models }\end{array}$ & - \\
\hline 8 & $\begin{array}{l}\text { Formal calculation up to 20 using numbers as mental } \\
\text { objects for smart and flexible calculation without the } \\
\text { need for structured materials }\end{array}$ & - \\
\hline 9 & Counting up to 100 & - \\
\hline 10 & Calculating up to 100 & $\begin{array}{l}\text { Approximately } \\
\text { age 9 (Grades 3-4) }\end{array}$ \\
\hline
\end{tabular}

Source: Van den Heuvel-Panhuizen, M. (2008). Children learn mathematics: A learningteaching trajectory with intermediate attainment targets for calculation with whole numbers in primary school. Rotterdam: Sense Publishers 
is primarily organised by an increasing number range. However, in its detail it refers back to the Treffers and Buys framework and its reference to structuring (Kühne et al., 2013, p. 83).

This is not the first, nor the only, learning-teaching trajectory for number concept development. For example, Murray and Olivier (1989) formulated a theoretical model describing four increasingly abstract levels of types of computational strategies with two-digit numbers in a given range: count all, counting on, decade wise counting (the medium number sequence), but with a multi-digit conception, and condensed column methods (pp. 5-7). In addition to supporting the global evidence that the shift from counting to calculating takes time (as evident in their South African empirical data), Murray and Olivier make an important observation: 'Level 3 understanding provides sufficiently powerful computational strategies, so that the introduction of the standard written algorithms may be delayed, if they should be taught at all' (p. 9).

Insight 3: As South African children learn base-ten place value in a multilingual context for number names, deep conceptual understanding may take additional time

The South African context is important here: most Foundation Phase children learn mathematics in African languages and are introduced to English as an additional language. Starting in Grade 2 children are expected to count orally with meaning up to 100 , and to write the number symbols up to 100 . Counting orally with meaning up to 100 means that children have to create an association between five aspects of each number: the visual stimulus, the chain of sounds for the spoken number word, the ten-wise place value structure of the number words, the written number words, and the number symbols (see Fuson \& Li, 2009; Fuson et al., 1997). They then change to learning mathematics in English in Grade 4.

Figure 3 illustrates the five aspects of the number 23, in the South African language context, where an African language (such as isiXhosa or Sesotho) as well as English proficiency with multi-digit numbers is required.

Using multi-digit number names with meaning requires children to notice word parts and associate these with decades and ones (Fuson \& Li, 2009). The number words for a multi-digit number are linked in a chain of sounds. In English, the number symbol ' 34 ' is said and heard as a continuous chain of sounds: 'thir-ty-four'. This often leads to children linking (concatenating) the number symbols when writing multi-digit numbers. So thirty-four is written incorrectly as ' 304 '. Place value is part of the how numbers are named in some African languages (as with Mandarin). This is not the case for English. When teaching in English, children must first learn that 'eleven' means ' 1 ten and 1 ', and twelve means ' 1 ten and 2 ' etc. In English the base-ten

\begin{tabular}{|c|c|c|c|c|}
\hline Aspect & Stimulus & English & isiXhosa & Sesotho \\
\hline 1 & $\begin{array}{l}\text { A visual stimulus depicting a } \\
\text { number of objects. } \\
\text { This could be imagined from } \\
\text { situation or a story problem, } \\
\text { or shown visually as concrete } \\
\text { objects, iconic pictures of a } \\
\text { set of objects, or a more } \\
\text { indexical depiction of the } \\
\text { objects. }\end{array}$ & & & \\
\hline 2 & $\begin{array}{l}\text { A chain of sounds which } \\
\text { makes up the number word }\end{array}$ & $\begin{array}{l}\text { twen-ty- } \\
\text { three }\end{array}$ & $\mid \begin{array}{l}\text { a-ma-shu-mi } \\
\text {-a-ma-bi-ni- } \\
\text { a-nan-ta-thu }\end{array}$ & $\begin{array}{l}\text { ma-sho-me } \\
\text {-a-ma-be-li- } \\
\text { a-me-tso-e- } \\
\text { me-ra-ro }\end{array}$ \\
\hline 3 & $\begin{array}{l}\text { The } 10 \text {-wise place value } \\
\text { structure implicit in the } \\
\text { number name, number } \\
\text { symbol }\end{array}$ & $\begin{array}{l}2 \text { tens an } \\
\text { (Transpar } \\
\text { isiXhosa } \\
\text { transpare }\end{array}$ & $\begin{array}{l}3 \text { units } \\
\text { nt in number } \\
\text { d Sesotho, bu } \\
t \text { for English) }\end{array}$ & $\begin{array}{l}\text { words for } \\
\text { t not }\end{array}$ \\
\hline 4 & $\begin{array}{l}\text { The number name written } \\
\text { using letters of the alphabet } \\
\text { and pronounced using a } \\
\text { chain of sounds. }\end{array}$ & $\begin{array}{l}\text { Twenty- } \\
\text { three }\end{array}$ & $\begin{array}{l}\text { amashumi } \\
\text { amabini } \\
\text { anantathu }\end{array}$ & $\begin{array}{l}\text { mashome a } \\
\text { mabeli a } \\
\text { metso e } \\
\text { meraro }\end{array}$ \\
\hline 5 & $\begin{array}{l}\text { A multi-digit number symbol } \\
\text { making use of only } 10 \text { digits } \\
(0,1,2 \ldots, 8,9)\end{array}$ & 23 & & \\
\hline
\end{tabular}

FIGURE 3: Five aspects of oral counting multi-digit numbers with understanding.

place value structure of numbers is not explicit in the English number names. The words 'three-tens-four' would be more regular and transparent than 'thirty-four'. Similarly, 'one-ten-three' would be more regular and transparent than 'thirteen'.

Becoming secure with these five associations between the visual stimuli (of the real or imagined aggregate, the written number word, the written number symbol) and oral stimuli (of the chain of sounds for the spoken number name) takes time. When reading and writing is not yet fluent this is more difficult. When two languages are at play, additional time is required. All of these associations - together with fluency in reading and writing number symbols and operators - are prerequisites for formal written calculation methods. As a result, the introduction of formal written methods ought to be delayed until use of written number symbols and spoken number names is secure.

Insight 4: The standard written algorithm has been found to be error prone and to support an incorrect 'single-digit-conception' of place value

There is much research that coheres on the finding that using a column method for addition and subtraction encourages a digit-wise conception rather than a multi-digit conception of large numbers. Fuson et al. (1997) refer to a 'concatenated single-digit conception'. The term 'concatenate' derives from the Latin 'con-' (link) and 'catenare' (chain). In this article I use the simple phrase 'digit-wise' to refer to 'concatenated single-digit'. With a digit-wise conception 234 is conceptualised as 'two-three-four' where each digit does 
not have its actual value. With a multi-digit conception, the magnitude of the number is explicit and 234 is conceptualised as ' 2 hundreds 3 tens and 4 ones'.

Various studies have shown that children may have an adequate multi-digit conception which they use for addition and subtraction calculations that are presented horizontally or in word problems. However, when presented with the same calculation vertically, they use a digit-wise conception and make errors (Fuson et al., 1997, citing Cobb and Wheatley, 1988, Davis, 1984, and unpublished South African data from Murray). These findings cohere with the low success rates in using the SWA evident among South African children (Murray \& Olivier, 1989).

Common errors in using the column algorithm are also documented by Kamii and Dominik (1997), including the misconception of digit-wise conceptions of number for calculating highlighted by Fuson et al. (1997). To avoid the digit-wise misconception, calculation methods for arithmetic emphasise a holistic concept of the numbers, where 'numbers are kept as wholes in any partition' (p. 41). As a result, in the early grades teachers are advised to avoid procedures that treat individual digits within a number independently. This caution applies to the SWA where individual digits are treated independently. Olivier (1992) argued that the SWA is prone to error 'because the techniques are difficult to understand relationally', explaining that regrouping (at times referred to carrying or borrowing) is probably the source of most errors with SWA (p. 217).

In their small-scale study of 21 Grade 4 students, Flanders, Torbeyns and Verschaffel (2013) found greater speed and accuracy when the written algorithm was used in comparison to mental computation. Significantly, this study was conducted with fourth graders (beyond Foundation Phase), and within an instructional culture 'wherein routine mastery of written algorithms was emphasised' (p. 139). In contrast, a recent study in France used a single subtraction word problem but had a larger sample of 2619 Grade 2 learners (Fischer et al., 2019). It found that the column method was the seventh most accurate out of the 11 strategies and associated representations used by the children. The authors found that 'a great number of students applied blindly the column procedure' with the most successful students using multiple procedures. As a result, Fischer et al. (2019) argued for 'delayed teaching of the written algorithm' (p. 13).

I therefore note that the SWA in the early grades (Grades R-3) has been found to encourage the incorrect digit-wise conception of the place value of multi-digit numbers and has been found to be error prone. Retaining numbers as whole numbers (such as 37 being 30 and 7) and not as digits ( 3 tens and 7 ones) in any partition is encouraged to avoid the digitwise conception of multi-digit numbers.

Insight 5: Cognitive load is an important consideration when reflecting on ways of recording the 'break up both numbers' strategy.
Given the above insights, it is not surprising that if it is to be used, the introduction and development of SWA needs to be slow and incremental to ensure that a robust conceptual understanding of place value is first established. Several alternative representations to record a 'break up both numbers strategy' appear in the education literature. Some of these make reference to manipulatives or concrete materials. Shifts towards arranging discrete objects or using structured materials in 5-wise and 10-wise groups are encouraged (Roberts, 2015; Saka \& Roberts, 2018).

In my experience, particularly with an urban small class setting, disruptive learner behaviour was a significant feature of the mathematics classroom (See Roberts \& Venkat, 2016). Using manipulatives in very large classes (of 45 or more) would also be unfeasible. The same was evident in the USA, where in a Foundation Phase intervention, Fuson and Li (2009) found that the use of manipulatives (bottle tops, dienes blocks, counters) created classroom management issues and were difficult to show to a whole class to explain multi-digit addition and subtraction. They therefore turned to using concrete materials only initially (to make 10-sticks or strips and 100-squares on centimetre dot grids). This initial introduction soon moved into making sketches of quick-10s and quick-100s using 5-wise groups so that a viewer could see quickly (at a glance) how many there were in a drawing, as shown in Figure 4.

Futon and Li's (2009) argument and suggested structured drawings draw on a review of Asian texts (Chinese, Korean and Japanese) as well as their empirical research with children using the Math Expressions texts in the USA. Fuson and Li (2009) offer various written methods for formal written calculations, but argue that the 'new groups below' and 'write all totals' (with its horizontal variation of 'expanded notation form') representations shown in Figure 5 are the most mathematically desirable and accessible addition methods.

Rather than have children overload their working memory, teachers should encourage children to:

- record intermediate steps (rather than expecting these to be held mentally)

- work flexibly in terms of either from 'right to left', or 'left to right'

- use structured drawings, together with expanded written methods.

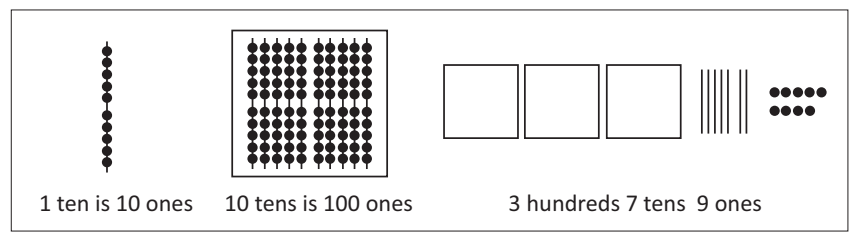

Source: Adapted from Fuson, K.C., \& Li, Y. (2009). Cross-cultural issues in linguistic, visualquantitative, and written-numeric supports for mathematical thinking. ZDM: The International Journal on Mathematics Education, 41, 793-808 (p. 801).

FIGURE 4: Mathematics drawings as a representation of place value. 


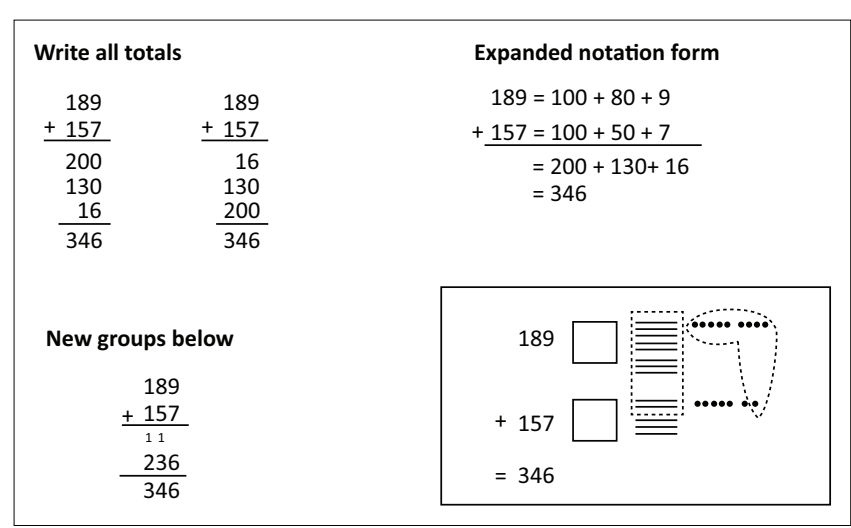

Source: Adapted from Fuson, K.C., \& Li, Y. (2009). Cross-cultural issues in linguistic, visualquantitative, and written-numeric supports for mathematical thinking. ZDM: The International Journal on Mathematics Education, 41, 793-808 (p. 803). https://doi. org/10.1007/s11858-009-0183-7

SWA, standard written algorithm.

FIGURE 5: Mathematics drawing and variations on SWA.

Methods that record intermediate steps (rather than expecting these to be held mentally), and that allow for flexible working in terms of from right to left, or left to right, are advocated for.

Insight 6: Mathematics Recovery and Everyday Mathematics both introduce multi-digit addition with invented strategies, then using a 'break up the second number' strategy (and only Everyday Mathematics offers expanded written methods for communicating the 'break up both numbers' strategy).

The two learning programmes reviewed, which have shown positive effects at a large scale, both prioritise learner invented strategies when operations are first introduced. They then guide learners towards multi-digit addition using a 'break up the second number' strategy.

In the Mathematics Recovery learning programme, Wright et al. (2006) make clear the prerequisite knowledge required for a child to be able to add and subtract multi-digit numbers, including: counting by tens off the decades (counting using the medium number sequence from any number), counting by hundreds off the hundreds (counting using the large number sequence from any number), and adding tens to any two-digit number. Their teaching activities make use of a 'break up the second number strategy' which can be represented on an empty number line or using bundling sticks (manipulatives in ones, tens and hundreds). Wright offers no teaching activities for the 'break up both numbers strategy'.

The authors of Everyday Mathematics are explicit in describing the first introduction to algorithms as an 'invented procedures phase': 'When they are first learning an operation, Everyday Mathematics students are asked to solve problems involving the operation before they have developed or learned systematic procedures for solving such problems' (Bell et al., no date, p. 4). In the Everyday Mathematics learning programme, the introduction of written algorithms for addition and subtraction are introduced in Grade 2, but proficiency in the use of at least one algorithm for each

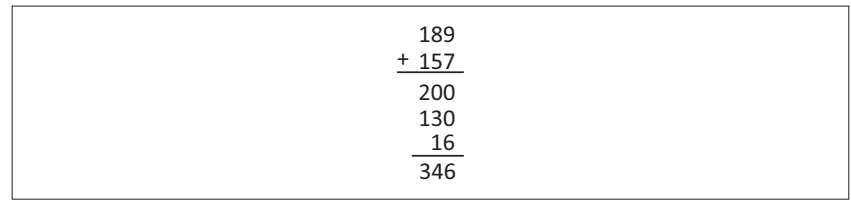

Source: Adapted from Bell, J., Bell, M., Bretzlauf, J., Dillard, Dairyko, M.A., Hartfield, R., .. Source: Adapted from Bell, J., Bell, M., Bretzlauf, J., Dillard, Dairyko, M.A., Hartfield, R., ... Mathematics Project. Columbus, $\mathrm{OH}$ : McGraw-Hill Education. Retrieved from from http:// everydaymath.uchicago.edu/

FIGURE 6: Example of 'Write all totals' or partial sums algorithm in Everyday Mathematics.

operation is only expected in Grade 4 . The SWA is not taught (although it may be introduced by children, via their parents). Interestingly, after its first few iterations, the authors of Everyday Mathematics introduced a common, widely accessible algorithm for each operation and considered this to be an important feature for classroom discussion. While children should invent and use a wide range of strategies, they chose to ensure that all children demonstrated familiarity with the 'write all totals' algorithm as its focal algorithm for addition (see Figure 6).

Notice that 'write all totals' is a four-step procedure (add the 100 s, add the 10s, add the 1s, add partial sums) which is recorded using columns. A digit-wise conception is avoided, as the 2 hundreds +4 hundreds is recorded as 600 (and not as 6 in the hundreds column). Similarly $60+80$ is recorded as 140 and not as 1 hundred, 4 tens and 0 ones. This representation in columns also allows learners to work either from left to right (starting with the 100s), or from right to left (starting with the 1s). Bell et al. (2015) note that children are inclined to work from left to right (when not directed by teachers to work from right to left), and that allows children to 'begin the problem-solving process with a reasonable estimate of what the final answer should be' (p. 8). This point is identified by Kamii and Dominick (1997) when they strongly asserted their rejection of algorithms:

Algorithms are harmful to children's development of numerical reasoning for two reasons: (a) They 'unteach' place value and discourage children from developing number sense, and (b) They force children to give up their own thinking. Children's natural way is to think about numbers from left to right. However, algorithms require them to give up this thinking and to proceed from right to left and to treat each column as ones. (p. 58)

Everyday Mathematics also offers another variation on the SWA (but not as its focal algorithm) but all addition of partial sums precedes any exchanges. See Figure 7.

The procedure here also allows flexible working from left to right, or from right to left. Notice here that there are two important reductions of cognitive load (compared to the SWA). Firstly, all addition is done before any exchanges take place. So rather than alternating processes (add then exchange as needed) the child can focus first on adding, and only later on exchanging. Secondly, the way of recording exchanges is documented in the relevant column to try and avoid a digitwise conception of place value (so 16 ones is recorded in the ones column, before it is exchanged to be 1 ten and 6 ones). 


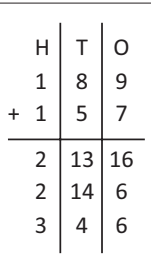

Source: Adapted from Bell, J., Bell, M., Bretzlauf, J., Dillard, Dairyko, M.A., Hartfield, R., .. Saeker, P. (2015). Everyday mathematics grades 1-3. University of Chicago Schoo Mathematics Project. Columbus, OH: McGraw-Hill Education. Retrieved from from http:// everydaymath.uchicago.edu/

SWA, standard written algorithm.

FIGURE 7: Everyday Mathematics variation of the SWA.

\section{How do the teacher guidelines on addition calculation strategies in the CAPS accord with, and differ from, those offered in the TMU framework?}

As a result of the above distinction between strategy and representation, when analysing the CAPS and TMU framework, strategies for addition were distinguished from the various representations that could be used as means of communication, as shown in Table 2.

The addition strategies (and their related grade progression) offered in the CAPS are shown in Figure 8.

The strategies, and the related progression, in CAPS are recognisable from the mathematics education literature. There are three important specifications relating to the expected progression for addition and subtraction techniques which are clearly stated in the CAPS and then exemplified in the clarification notes offered to teachers:

- Adding and subtracting are considered together - with emphasis placed on using these operations as inverses. As such the structural relationship between a number triple (like 5-3-2) is made explicit. Teachers are expected to emphasise that subtraction can be checked using addition $(5-3=\ldots$, can be considered as $3+\ldots=5)$. There is therefore an emphasis on families of related number sentences for each addition or subtraction fact.

- In Foundation Phase 'break down the second number' is a strong focus as this can be utilised for both addition and subtraction without the need for regrouping.

- Adding and subtracting in columns is delayed to Grade 5. In term 1 a 'write all totals' representation for the 'break up both numbers strategy' is presented. From term 2 onwards this is complemented by a SWA.

More detail about the CAPS suggested progression for addition and subtraction strategies is evident in the clarification notes for teachers. Figure 9 documents the addition strategies presented in the Foundation Phase (DBE, 2012a) and Intermediate Phase (DBE, 2012b) CAPS clarification notes by grade. To facilitate comparison, I have included the page numbers in the TMU framework that depict the same strategies (DBE, 2018).

It should be noted, however, that progression in relation to the strategies for addition and subtraction (and the flexible use of various representations to record these strategies) is
TABLE 2: Strategies and representation for addition in CAPS

\begin{tabular}{ll}
\hline Strategies for addition calculations & $\begin{array}{l}\text { Representations of addition calculations } \\
\text { (how the strategy is recorded) }\end{array}$ \\
\hline 1. Count all & - Concrete apparatus (counters, bead \\
2. Count on & - strings, abaci) \\
3. Break down the second number & - Number lines (structured or empty) \\
4. Break down both numbers & - Number sentences using number symbols \\
5. Use known or derived facts & and operations \\
& - A whole-part-part diagram \\
& - A triad or number triple \\
& - Calculator \\
& - Horizontal number sentences \\
& - Column or vertical methods \\
\hline
\end{tabular}

Source: Adapted from Department of Basic Education. (2012a). Curriculum and assessment policy statement: Mathematics foundation phase (pp. 14-23). Pretoria: DBE

CAPS, Curriculum and Assessment Policy Statements

\begin{tabular}{|c|c|c|c|c|c|c|c|}
\hline \multirow[b]{2}{*}{$\begin{array}{l}\text { Strategies (as labelled and referred } \\
\text { to in CAPS) }\end{array}$} & \multicolumn{4}{|c|}{ Foundation Phase } & \multicolumn{3}{|c|}{ Intermediate Phase } \\
\hline & $\begin{array}{l}\frac{\pi}{0} \\
\frac{1}{\pi} \\
\frac{\pi}{0}\end{array}$ & $\begin{array}{l}\text {-1 } \\
\frac{0}{0} \\
\frac{\pi}{0} \\
\text { ज }\end{array}$ & $\begin{array}{l}\text { N } \\
\frac{0}{0} \\
\frac{\pi}{0} \\
\text { U. }\end{array}$ & 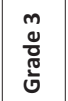 & 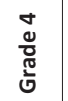 & 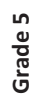 & 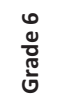 \\
\hline 1. Count all & \multicolumn{4}{|c|}{ p. 21} & & & \\
\hline 2. Count on & & \multicolumn{3}{|c|}{ p. 23} & & & \\
\hline 3. Break down the second number & & \multicolumn{3}{|c|}{ p. 21} & \multicolumn{3}{|l|}{ p. 14} \\
\hline Fill up the tens $\dagger$ & & & & p. 21 & & & \\
\hline Rounding off and compensating $\$$ & & & & & \multicolumn{3}{|l|}{ p. 14} \\
\hline 4. Break down both numbers & & & & & \multicolumn{3}{|l|}{ p. 14} \\
\hline $\begin{array}{l}\text { Break down both numbers using } \\
\text { expanded notation }\end{array}$ & & \multicolumn{3}{|c|}{ p. 21} & \multicolumn{3}{|l|}{ p. 14} \\
\hline $\begin{array}{l}\text { Break down both numbers using } \\
\text { place value }\end{array}$ & & & & & & \multicolumn{2}{|c|}{ p. 14} \\
\hline Estimation & & & & & \multicolumn{3}{|l|}{ p. 14} \\
\hline 5. Use known or given facts & & & & & & & \\
\hline Doubling and halving & & \multicolumn{3}{|c|}{ p. 21} & \multicolumn{2}{|l|}{ p. 14} & \\
\hline $\begin{array}{l}\text { Using addition and subtraction as } \\
\text { inverses }\end{array}$ & & & & & \multicolumn{3}{|c|}{ p. 14} \\
\hline \multicolumn{8}{|l|}{ Representations or tools } \\
\hline Number lines & & \multicolumn{3}{|c|}{ p. $21 ;$ p. 23} & p. 14 & & \\
\hline Adding and subtracting in columns & & & & & & \multicolumn{2}{|c|}{ p. 14} \\
\hline Calculator & & & & & & & p. 14 \\
\hline
\end{tabular}

Source: Adapted from Department of Basic Education. (2012a). Curriculum and assessment policy statement: Mathematics foundation phase (pp. 14-23). Pretoria: DBE

CAPS, Curriculum and Assessment Policy Statements.

$\dagger$, In CAPS this strategy is referred to as 'round off in tens'

$\$$ 'Rounding off and compensating' refers to examples like $37+9$, where 9 is rounded off to 10 , and then 1 is subtracted to compensate. So $37+9=37+10-1$.

FIGURE 8: Grade progression for addition calculation strategies in CAPS.

not made explicit in the CAPS document. It only becomes apparent when the entire document is analysed in relation to the expectations at each grade level.

When comparing CAPS to the TMU framework it should be noted that the latter only offers a limited number of exemplar tasks. The examples chosen for Foundation Phase relate to addition and subtraction of whole numbers, whereas the examples chosen for Intermediate Phase relate to rational numbers (common fractions in particular). It is therefore to be expected that the TMU framework is less comprehensive than the CAPS. It is nevertheless instructive to note which example types were omitted from the TMU framework exemplars. The five main strategies in the CAPS each feature in the framework. The particular strategies not referred to in the TMU framework are made explicit in Table 3.

The TMU framework has much in common with the CAPS. By way of example, both the CAPS and the TMU framework 


\begin{tabular}{|c|c|c|c|c|c|c|c|}
\hline Strategies & Grade R & Grade 1 & Grade 2 & Grade 3 & Grade 4 & Grade 5 & Grade 6 \\
\hline \multicolumn{8}{|l|}{ 1. Count all } \\
\hline \multirow{2}{*}{$\begin{array}{l}\text { (a) build up and break down } \\
\text { collections }\end{array}$} & p. 19 & pp. $142,109,110,143$ & & & & & \\
\hline & & \multicolumn{2}{|c|}{ The framework (pp. 23-24, p. 32) } & & & & \\
\hline (b) build up numbers in ones & p. 18 & p. 140 & & & & & \\
\hline \multicolumn{8}{|l|}{ 2. Count on } \\
\hline \multirow[t]{2}{*}{ (a) in ones } & pp. 70,201 & pp. 109,140 & p. 320 & pp. $390,422,424$ & & & \\
\hline & & \multicolumn{3}{|c|}{ The framework (pp.23-24) } & & & \\
\hline (b) from the bigger & & pp. 141,144 & p. 169 & pp. 229,361 & & & \\
\hline (c) in tens and ones & & & & & p. 66 & & \\
\hline \multicolumn{8}{|l|}{ 3. Break up the second number } \\
\hline \multirow[t]{2}{*}{ (a) fill up the tens $\dagger$} & & p. 168 & pp. 229, 261, 289, 319 & p. 347 & pp. 44,70 & p. 133 & \\
\hline & & \multicolumn{3}{|c|}{ The framework (pp. 27, 31) } & & & \\
\hline (b) into any parts & & p. 194 & & pp. 390,421 & & & \\
\hline \multirow[t]{2}{*}{ (c) use expanded notation } & & & pp. 269,320 & pp. $389,390,353,421$ & p. 44 & p. 123 & \\
\hline & & \multicolumn{3}{|l|}{ The framework (p. 30) } & & & \\
\hline \multicolumn{8}{|l|}{ 4. Break up both numbers } \\
\hline \multirow[t]{2}{*}{ (a) use place value horizontally } & & & & & p. 44 & pp. 134,157 & \\
\hline & & \multicolumn{3}{|l|}{ The framework (p. 32) } & & & \\
\hline $\begin{array}{l}\text { (b) use place value vertically } \\
\text { (expanded method) }\end{array}$ & & & & & & p. 158 & p. 223 \\
\hline (c) use place value vertically (SWA) & & The framework (p. 32) & & & & p. 182 (term 3) & p. 224 (term 1) \\
\hline \multicolumn{8}{|l|}{ 5. Build on known or given facts } \\
\hline $\begin{array}{l}\text { (a) the relationship between } \\
\text { addition and subtraction }\end{array}$ & & pp. 144,169 & pp. 321,320 & pp. 356,393 & pp. 36,40 & pp.123, 127 & p. 223 \\
\hline \multirow[t]{2}{*}{ (b) near doubles } & & p. 169 & pp. $229,266,320$ & p. 391 & p. 52 & p. 123 & p. 222 \\
\hline & & \multicolumn{3}{|l|}{ The framework (p. 30). } & & & \\
\hline (c) halves & & & p. 263 & pp. $354,390,361,422$ & p. 52 & p. 123 & p. 222 \\
\hline \multirow[t]{2}{*}{ (d) pairs that make ten } & & & p. 266 & & & & \\
\hline & & \multicolumn{3}{|l|}{ The framework (p. 32). } & & & \\
\hline \multirow[t]{2}{*}{ (e) rounding off and compensating } & & & p. 263 & pp. 355,391 & & po. 123,135 & p. 222 \\
\hline & & \multicolumn{3}{|l|}{ The framework (p. 32). } & & & \\
\hline \multirow{2}{*}{$\begin{array}{l}\text { (f) use given facts (inverse } \\
\text { relationship and 'if... then...') }\end{array}$} & & p. 77 & pp. $60,77,194,230$ & p. 323 & pp.36, 40 & & pp. 222,223 \\
\hline & & \multicolumn{3}{|l|}{ The framework (p. 31) } & & & \\
\hline $\begin{array}{l}\text { (g) formal reference to commutative } \\
\text { and associative properties }\end{array}$ & & & & & p. 41 & p. 118 & p. 218 \\
\hline
\end{tabular}

Source: Adapted from Department of Basic Education. (2012a). Curriculum and assessment policy statement: Mathematics foundation phase. Pretoria: DBE; Department of Basic Education. (2012b). Curriculum and assessment policy statement: Mathematics intermediate phase. Pretoria: DBE; Department of Basic Education. (2018). Mathematics teaching and learning framework for South Africa: Teaching mathematics for understanding. Pretoria: DBE

CAPS, Curriculum and Assessment Policy Statements; TMU, Mathematics teaching and learning framework for South Africa: Teaching mathematics for understanding; SWA, standard written algorithm.

$\dagger$, This may also be called 'make a ten' or 'bridge ten'.

FIGURE 9: Addition strategies presented in CAPS clarification notes and the TMU framework.

recognise the need for learners to use any strategy, but that teachers should encourage them away from unit counting, towards more efficient strategies, and ways of recording calculations.

The TMU framework offers an example of $29+15=\ldots$ where learners are expected to 'use any method'. It also includes examples of 'break up both numbers' strategy using manipulatives (p. 26 and p. 27), 'break up the second number in expanded notation' strategy recording this using number sentences and on a number line (p. 27), and 'break up the second number' to fill up the tens, recording this on a number line (p. 28).

A major distinction between the TMU framework and CAPS is the suggestion in the TMU framework for teachers to introduce the SWA in the Foundation Phase (Grades R-3). In the TMU framework the SWA is offered as a way to record $34+37=\ldots$ using a 'break up both numbers' strategy (shown in Figure 10). 
TABLE 3: Appearance of Foundation Phase strategies in CAPS and TMU framework

\begin{tabular}{|c|c|c|c|}
\hline $\begin{array}{l}\text { Main } \\
\text { strategies }\end{array}$ & $\begin{array}{l}\text { In both CAPS and the } \\
\text { TMU framework }\end{array}$ & Only in CAPS & $\begin{array}{l}\text { Only in TMU } \\
\text { framework }\end{array}$ \\
\hline Count all & $\begin{array}{l}\text { - build up and break } \\
\text { down collections }\end{array}$ & $\begin{array}{l}\text { - build up numbers } \\
\text { in ones }\end{array}$ & - \\
\hline Count on & - in ones & $\begin{array}{l}\text { - from the bigger } \\
\text { - in tens and ones }\end{array}$ & - \\
\hline $\begin{array}{l}\text { Break up the } \\
\text { second number }\end{array}$ & $\begin{array}{l}\text { - fill up the tens } \\
\text { - use expanded notation }\end{array}$ & - into any parts & - \\
\hline $\begin{array}{l}\text { Break up both } \\
\text { numbers }\end{array}$ & $\begin{array}{l}\text { - use place value } \\
\text { horizontally }\end{array}$ & - & $\begin{array}{l}\text { - use place value } \\
\text { vertically (SWA) }\end{array}$ \\
\hline $\begin{array}{l}\text { Build on known } \\
\text { or given facts }\end{array}$ & $\begin{array}{l}\text { - pairs that make ten } \\
\text { - near doubles } \\
\text { - rounding off and } \\
\text { compensating } \\
\text { - use given facts } \\
\text { (inverse relationship } \\
\text { and 'if... then...') }\end{array}$ & $\begin{array}{l}\text { - use the } \\
\text { relationship } \\
\text { between addition } \\
\text { and subtraction } \\
\text { - halves }\end{array}$ & - \\
\hline
\end{tabular}

Source: Adapted from Department of Basic Education. (2012a). Curriculum and assessmen policy statement: Mathematics foundation phase. Pretoria: DBE; Department of Basic Education. (2018). Mathematics teaching and learning framework for South Africa: Teaching mathematics for understanding. Pretoria: DBE

CAPS, Curriculum and Assessment Policy Statements; TMU, Mathematics teaching and learning framework for South Africa: Teaching mathematics for understanding; SWA standard written algorithm.

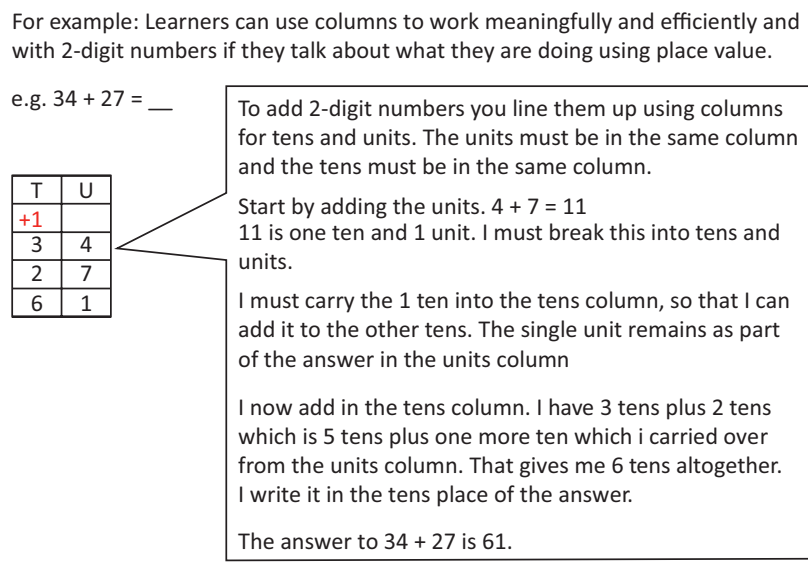

The number work of exchanging the ten units for 1 ten should be linked to concrete work done using base ten blocks where learners see how to exchange ten units for 1 ten. This will guide them to understand the conceptual sturcture embodied in the algorithm. This conceptual work under pinning the procedure (which again highlights the interconnectedness of the framework dimensions) will prevent learners from following the steps of the procedure without thinking about the meaning behind what they are doing. This applies to all methods of calculation.

Source: Department of Basic Education. (2018). Mathematics teaching and learning framework for South Africa: Teaching mathematics for understanding (p. 32). Pretoria: DBE SWA, standard written algorithm; TMU, Mathematics teaching and learning framework for South Africa: Teaching mathematics for understanding.

FIGURE 10: An example of SWA to solve $34+27=\ldots$ in the Foundation Phase exemplars of the TMU framework.

The vertical column method to add.

$$
\begin{aligned}
& \begin{array}{lllll}
1 & 1 & 1 & & \\
5 & 6 & 4 & 2 & 3
\end{array} \\
& \begin{array}{r}
5481 \\
+\quad 7504
\end{array}
\end{aligned}
$$

Source: Department of Basic Education. (2012b). Curriculum and assessment policy statement: Mathematics intermediate phase (p. 157). Pretoria: DBE

SWA, standard written algorithm; CAPS, Curriculum and Assessment Policy Statements.

FIGURE 11: First example of SWA in CAPS for Intermediate Phase.

This differs from the guidance offered to teachers in the CAPS, where any use of written methods in columns is delayed to Grade 5 (DBE, 2012b, p. 157). It is only in term 3 of Grade 5 that the SWA appears in the CAPS guidelines for the first time, as shown in Figure 11.
In addition, in the TMU framework the SWA is the only representation for the 'break up both numbers' strategy, and no examples of expanded written methods are offered. As such the TMU makes a major departure from CAPS when it suggests that teachers should make use of concrete apparatus to work with 'breaking down both numbers' into expanded notation in order to introduce the SWA in Foundation Phase.

\section{Conclusion}

I have shown that both the CAPS and the TMU framework emphasise the need to teach mathematics for understanding. I have argued that the desired understanding is relational understanding ('knowing what to do and why') not instrumental understanding ('rules without reasons'). I have argued that this is in line with the mathematics reform agenda where the desired transformation of mathematics teaching is away from teaching meaningless procedures towards teaching mathematics that builds directly on learners' entry knowledge and skills, provides opportunities for inventions and practice, focuses on the analysis of (multiple) methods, and expects learners to provide explanations.

I point out that the CAPS does not clarify the distinction between strategies, representations and procedures. I suggest, drawing on the TMU framework, that distinctions between a strategy (way of thinking), a representation (how such thinking is recorded), and a procedure (a generalised stepby-step rule or process on how to create a particular representation to depict a particular strategy) ought to be made explicit. I also note that the expected progression in relation to the strategies for addition and subtraction (and the flexible use of various representations to record these strategies) is not made overt in the CAPS document and is only evident when a grade by grade level analysis of strategies is conducted.

I make explicit my belief in the value of inculcating both conceptual understanding and procedural fluency. I emphasise that this does not mean I think algorithms should be the starting points of mathematical learning. Nor does my belief imply that the elegant and formal SWA ought to be a desired destination for all children. In fact, we know that the highly condensed SWA was used in a time when accuracy and efficient were most prized. In our current context - with ubiquitous access to calculators (in computers and mobile phones) - efficiency and accuracy are not as highly valued. The process of inventing, refining and reflecting on algorithms coupled with the ability to communicate with others about multiple strategies, and various ways of representing these, is of far greater importance and value. It is for this reason that I attend carefully to how I think formal written algorithms ought to be introduced to young children, and why I attend to various options for recording these (likely to suit a wider range of children), which I present in Appendix 1.

We know from both local and international literature that early introduction of the SWA for addition and subtraction 
supports the incorrect digit-wise conception of place value for multi-digit numbers. We also know that deep conceptual understanding of place value is predictive of future mathematics attainment, that there are five correct conceptions of place value, each of which takes time to develop, and that the development from rote counting to efficient calculation takes about 7 years. The South African curriculum (CAPS) seems to build on this literature as it encourages a slow progression in relation to the development of the place value concept and progression with regard to efficiency of calculation strategies. In contrast, the TMU deviates from both the CAPS and the international literature. It proposes that the SWA for addition can be modelled using manipulatives, and then used as a written method with digitwise tens and ones columns in Foundation Phase.

In addition, the TMU does not include the expanded column methods (such as 'write all totals' - either horizontally or vertically, which appear in CAPS) as possible alternatives to the SWA. The expectation created in the TMU framework is that teachers can shift from bundling concrete manipulatives for multi-digit numbers to the SWA in Grades R-3. This contradicts both the CAPS and insights reported on above. The TMU framework is also discordant with the two learning programmes - Everyday Mathematics and Mathematics Recovery - where addition is introduced using a 'break up the second number' (which can be applied to subtraction without the need for regrouping or exchanges) before the 'break up both numbers' strategy is introduced. 'Break up both numbers' is considered in Everyday Mathematics. When 'break up both numbers' is introduced, the SWA is avoided and the expanded method of 'write all totals' is the focal algorithm (to be understood but not necessarily used by all learners).

Given how much conceptual knowledge for place value is to be constructed - and its critical importance in mathematical progression - the move from concrete manipulatives to the SWA suggested in the TMU framework is too rapid. The introduction of the SWA in Foundation Phase, when it is only in Grade 2 that notions of place value are beginning to be constructed by learners, is too soon. This creates a lack of clarity in our policy landscape, which is only partially clarified by the repeated assertion that the TMU framework does not replace CAPS.

So, if asked whether, when and how to teach the SWA, I would respond as follows. While some mathematics educators reject the teaching of SWA in its totality, I think exposure to algorithms in their historic context is worthwhile. As the SWA is familiar to South African teachers, I think it is worthwhile for children to understand it, without emphasising speed and accuracy. However, I do not think it should be taught in Foundation Phase. I concur with the CAPS that the SWA should only be introduced in Grade 5 when place value in two languages is secure. In Foundation Phase I would teach multi-digit addition by first encouraging children's invented strategies, then offering structured mathematics drawings and expanded methods. I would use 'write all totals' as a 'go-to' algorithm for the whole class.
Only once 'write all totals' is secure would I introduce the SWA as an optional condensed method, which was used at a particular time in history, when speed and accuracy were valued.

\section{Acknowledgements}

This article results from a symposium at the National Science and Technology Forum in August 2018. I wish to thank all the mathematics education colleagues who took part in the robust debates at, and following, this symposium. In addition, I received invaluable critical feedback, which substantially changed this article, from colleagues within the curriculum unit of the DBE, and academic colleagues who reviewed the first version of this article. Discussion with international colleagues emanating from an oral communication on this issue at the Psychology of Mathematics Education (PME-43) conference was also very helpful. All of these role players share a common concern for improving mathematics in South Africa which was evident in their critical engagement and generosity in sharing ideas.

\section{Competing interests}

I declare that I have no financial or personal relationships that may have inappropriately influenced me in writing this article.

\section{Authors' contributions}

I declare that I am the sole author of this article.

\section{Ethical consideration}

No children were involved in collection of empirical data for this article; therefore no ethical clearance was applied for.

\section{Funding information}

This research received no specific grant from any funding agency in the public, commercial of not-for-profit sectors.

\section{Data availability statement}

Data sharing is not applicable in this article as no new data were created or analysed in this study.

\section{Disclaimer}

The views and opinions expressed in this article are those of the authors and do not necessarily reflect the official policy or position of any affiliate agency of the authors.

\section{References}

\footnotetext{
Anghileri, J. (2000). Teaching number sense (2nd ed.). London: Continuum.

Bell, J., Bell, M., Bretzlauf, J., Dillard, Dairyko, M.A., Hartfield, R., ... Saeker, P. (2015). Everyday mathematics grades 1-3. University of Chicago School Mathematics Project. Columbus, OH: McGraw-Hill Education. Retrieved from http://everydaymath. uchicago.edu/

Bell, J., Bell, M., Bretzlauf, J., Dillard, Dairyko, M.A., Hartfield, R., ... Saeker, P. (n.d.). Algorithms in everyday mathematics. University of Chicago School Mathematics Project. Retrieved from http://everydaymath.uchicago.edu/about/research-results/ algorithms.pdf
} 
Carpenter, T., \& Fennema, E. (1999). Children's mathematics: Cognitively guided instruction. Portsmouth, $\mathrm{NH}$ : Heinemann.

Carpenter, T., Franke, M., \& Levi, L. (2003). Thinking mathematically: Integrating arithmetic and algebra in elementary school. Portsmouth, NH: Heinemann.

Department of Basic Education. (2012a). Curriculum and assessment policy statement Mathematics foundation phase. Pretoria: DBE. Retrieved from https://www. education.gov.za/Portals/0/CD/National\%20Curriculum $\% 20$ Statements $\% 20$ and $\% 2$ Vocational/CAPS $\% 20$ MATHS $\% 20 \% 20$ ENGLISH $\% 20$ GR $\% 201-3 \% 20$ FS. pdf?ver=2015-01-27-160947-800

Department of Basic Education. (2012b). Curriculum and assessment policy statement Mathematics intermediate phase. Pretoria: DBE. Retrieved from https://www. education.gov.za/Portals/0/CD/National\%20Curriculum $\% 20$ Statements $\% 20$ and $\% 20$ Vocational/CAPS $\% 20$ IP $\% 20 \% 20$ MATHEMATICS $\% 20$ GR $\% 204-6 \% 20$ web. pdf?ver=2015-01-27-161430-553

Department of Basic Education. (2018). Mathematics teaching and learning framework for South Africa: Teaching mathematics for understanding. Pretoria: DBE. Retrieved from https://www.education.gov.za/Portals/0/Documents/Publications/ MatHEMATICS\%20TEACHING\%20and\%20LEARNING\%20FRAMEWORK $\% 20$ draft $\% 206$.pdf?ver=2019-06-05-111354-387

Ernest, P. (2014). Policy debates in mathematics education. In S. Lerman (Ed.), Encyclopedia of mathematics education (pp. 480-484.) Dordrecht: Springer. https://doi.org/10.1007/978-94-007-4978-8_125

Fischer, J-P., Vilette, B., Joffredo-Lebrun, S., Morellato, M., Le Normand, C., Scheibling Seve, C., \& Richard, V-F. (2019). Should we continue to teach standard written algorithms for the arithmetical operations? The example of subtraction. Educational Studies in Mathematics, 101(1), 1-17. https://doi.org/10.1007/ s10649-019-09884-9

Fuson, K.C., \& Li, Y. (2009). Cross-cultural issues in linguistic, visual-quantitative, and written-numeric supports for mathematical thinking. ZDM: The International Journal on Mathematics Education, 41, 793-808. https://doi.org/10.1007/s11858009-0183-7

Fuson, K.C., Wearne, D., Hiebert, J.C., Murray, H.G., Human, P.G., Olivier, A.I, ... Fennema, E. (1997). Children's conceptual structures for multidigit numbers and methods of multidigit addition and subtraction. Journal for Research in Mathematics Education, 28(2), 130-162. https://doi.org/10.2307/749759

Goldin, G.A. (2014). Mathematical representations. In S. Lerman (Ed.), Encyclopedia of mathematics education (pp. 409-411). Dordrecht: Springer. https://doi.org/ 10.1007/978-94-007-4978-8_103

Hiebert, J. (1999). Relationships between research and NCTM Standards. Journal for Research Mathematics Education, 30(1), 3-19. https://doi.org/10.2307/ 749627

Kamii, C., \& Dominick, A. (1997). To teach or not to teach algorithms. The Journal of Mathematical Behavior, 16(1), 51-61. https://doi.org/10.1016/S0732-3123(97) 90007-9

Kilpatrick, J., Martin, W., \& Schifter D. (Eds.). (2003). A research companion to principles and standards for school mathematics. Reston, VA: NCTM.

Kilpatrick, J., Swafford, J., \& Findell, B. (Ed.). (2001). Adding it up: Helping children learn mathematics. Washington, DC: National Academy Press.

Kühne, C., Lombard, A.-P., \& Moodley, T. (2013). A learning pathway for whole numbers that informs mathematics teaching in the early years. South African Journal of Childhood Education, 3(2), 77-95. https://doi.org/10.4102/sajce.v3i2.42

Murray, H., \& Olivier, A. (1989). A model of understanding two-digit numeration and computation. In G. Vergnaud, J. Rogalski, \& M. Artigue (Eds.), Proceedings of the 13th Annual Conference of the International Group for the Psychology of Mathematics Education (Vol. 3, pp. 3-10). Paris: PME. Retrieved from https:// Mathematics Education (Vol. 3, pp. 3-10
files.eric.ed.gov/fulltext/ED411142.pdf
Olivier, A. (1992). Computations skills for the year 2001. In M. Moodley, R. Njisan, \& N. Presmeg (Eds.), Mathematics education for in-service and pre-service teachers (pp. 210-221). Pietermaritzburg: Shuter \& Shooter.

Riordan, J., \& Noyce, P., (2001). The impact of two standards-based mathematics curricula on student achievement in Massachusetts. Journal for Research in Mathematics Education, 32(4), 368-398. https://doi.org/10.2307/749700

Roberts, N. (2015). Interpreting children's representations of whole number additive relations in the early grades. In X. Sun, B. Kaur, \& J.Novotná (Eds.), Conference Proceedings of ICMI Study 23: Primary Mathematics Study on Whole Numbers (pp. 243-250). Macao: ICMI. Retrieved from https://www.um.edu.mo/fed/ ICMI23/doc/Proceedings_ICMI_STUDY_23_final.pdf

Roberts, N. (2017). A historical and socio-political perspective on mathematics education in South Africa. In P. Webb \& Roberts, N. (Eds.), The pedagogy of mathematics in South Africa: Is there a unifying pedagogy? (pp. 41-66). Johannesburg: Mistra and Real Africa Publishers.

Roberts, N., \& Venkat, H. (2016). Learning from disruptive classroom behaviour in a Grade 2 mathematics lesson. South African Journal of Childhood Education, 6(1), a377. https://doi.org/10.4102/sajce.v6i1.377

Saka, T.W., \& Roberts, N. (2018). Manipulatives for early grade whole number and relationships: The potential of the Malawian bow-abacus. In R. Govender \& K. Junqueira (Eds.), Proceedings of the 24th Annual National Congress of the Association for Mathematics Education of South Africa (pp. 391-406). Bloemfontein: AMESA. Retrieved from http://www.amesa.org.za/AMESA2018/ Volume1.pdf

Skemp, R. (1987). The psychology of learning mathematics. New York, NY:Routledge.

Star, J. (2014). Instrumental and relational understanding in mathematics education. In S. Lerman (Ed.), Encyclopedia of mathematics education (pp. 304-307). Dordrecht Springer. https://doi.org/10.1007/978-94-007-4978-8_79

Thomas, M. (2014). Algorithms. In S. Lerman (Ed.), Encyclopedia of mathematics education (pp. 36-38). Dordrecht: Springer. https://doi.org/10.1007/978-94-0074978-8_8

Torbeyns, J., \& Verschaffel, L. (2013). Efficient and flexible strategy use on multi-digit sums: A choice/no-choice study. Research in Mathematics Education, 15(2), 129140. https://doi.org/10.1080/14794802.2013.797745

Treffers, A. (2008a). Kindergarten 1 and 2 - Growing number sense. In M. Van den Heuvel-Panhuizen (Ed.), Children learn mathematics: A learning teaching
trajectory with intermediate attainment targets for calculation with whole trajectory with intermediate attainment targets for calculation
numbers in primary school (pp. 31-42). Rotterdam: Sense Publishers.

Treffers, A. (2008b). Grade 1 (and 2) - Calculation up to 20. In M. Van den HeuvelPanhuizen (Ed.), Children learn mathematics: A learning teaching trajectory with
intermediate attainment targets for calculation with whole numbers in primary school (pp. 43-50). Rotterdam: Sense Publishers.

Treffers, A., \& Buys, K (2008). Grade 2 (and 3) - Calculation up to 100. In M. Van den Heuvel-Panhuizen (Ed.), Children learn mathematics: A learning teaching trajectory with intermediate attainment targets for calculation with whole numbers in primary school (pp. 61-88). Rotterdam: Sense Publishers.

Van den Heuvel-Panhuizen, M. (2008). Children learn mathematics: A learning teaching trajectory with intermediate attainment targets for calculation with whole numbers in primary school. Rotterdam: Sense Publishers. https://doi.org/ 10.1163/9789087903954_004

Ward, W. (2009). The influence of a reform-based mathematic program on third, fourth, and fifth grade student achievement. Unpublished doctoral dissertation, Seton Hall University, South Orange, NJ. Retrieved from https://scholarship.shu. edu/dissertations/1614

Wright, R., Martland, J., Stafford, A., \& Stanger, G. (2006). Teaching number: Advancing children's skills and strategies (2nd ed.). London: Paul Chapman Publishing. 


\section{Appendix 1: Key terms used in this article}

Digit: $\quad$ The number symbols 0 to 9 which are used to represent all numbers.

Digit-wise: Naming and thinking about a multi-digit number as comprising of its digits. 356 is 'three five six'.

Unit-wise: Depicting a number as comprising units (or ones).

Five-wise: Depicting a number as comprising groups of 5.

Ten-wise: Depicting a number as comprising groups of 10 . This may include showing each ten as comprising 2 fives.

Quick 5: A drawing or arrangement in which the objects or markings are spatially arranged so that it is quick and easy to identify groups of 5. Quick 10: A drawing or arrangement in which the objects or markings are spatially arranged so that it is quick and easy to identify groups of 10.

Quick 100: A drawing or arrangement in which the objects or markings are spatially arranged so that it is quick and easy to identify groups of 100.

Structured mathematics drawing: A drawing that clearly shows the five-wise and ten-wise structure of numbers.

Structured apparatus: Apparatus which clearly shows the five-wise and ten-wise structure of a number such as an abacus or a 5-5-5-5 bead string.

Small number sequence: Counting in ones from any number. 15, 16, 17, 18, ...

Medium number sequence: Counting in tens from any number. $15,25,35,45, \ldots$

Large number sequence: Counting in hundreds from any number. $15 ; 115,215,315,415, \ldots$

Triad: A set of 3 numbers that form an additive relationship. This is also termed a 'number triple'.

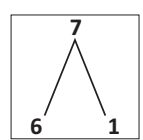

Whole-part-part diagram: A diagram depicting a whole and two parts of an additive relationship. This is a triad or number triple, where a context of length is applied.

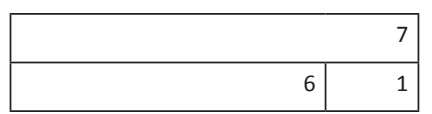

Structured number line: A number line marked in ones

Semi-structured number line: A number line marked in fives or tens

Empty number line: A number line with no structured markings

Place value: The value of a digit according to its position in a multi-digit number. So the 3 in in 356 , has a place value of 3 hundred.

Expanded notation: Break up a number using the place value of each digit. So $356=300+50+6$ 


\section{Appendix 2: Representations for addition strategies}

The SWA, which is familiar to many adults, is a very condensed version of a 'break up both numbers' strategy. But the mathematics education literature, and the example learning programmes, encourage invented strategies, and a 'break up the second number' strategy, before children are exposed to the 'break up both numbers' strategy. In this Annexure, I show how each strategy may be represented.

\section{Representations for 'break up the second number' strategy}

If being introduced by a teacher (and not brought or invented by a learner), this strategy should precede the 'break up both numbers' strategy. This strategy can be used for addition and subtraction and no regrouping (exchanging, borrowing or carrying is needed). This strategy can also be used flexibly for missing addend and missing subtrahend problems (such as $189+\ldots=346$; or $346-\ldots=189$ ).

Notice that the 'break up the second number' strategy means you don't break up the first number as well. In these examples you always start with 189 , which is the first number in $189+157=\ldots$

\section{Expanded notation on an empty number line}

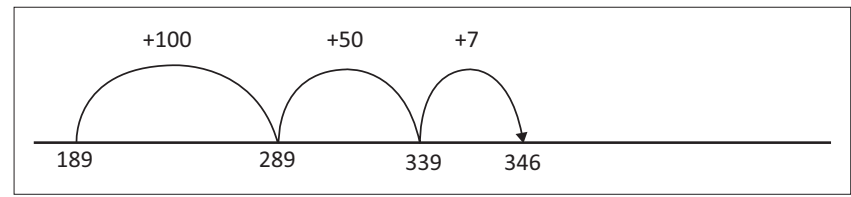

\section{Expanded notation and number sentences}

$$
\begin{array}{r}
189+100=289 \\
289+50=339 \\
339+7=346
\end{array}
$$

\section{Fill up the tens on an empty number line}

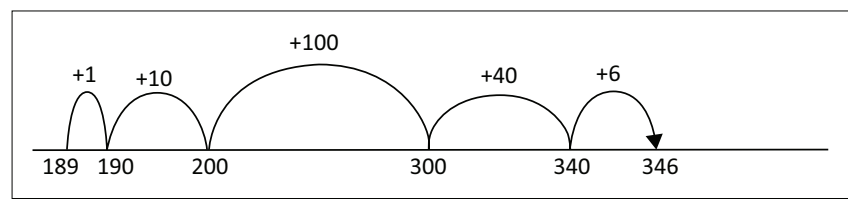

\section{Representations for 'break up both numbers' strategy}

If being introduced by a teacher (and not brought or invented by a learner), this strategy should be used after learners are secure with the 'break up both numbers' strategy for both addition and subtraction. Depending on the numbers, this strategy may require regrouping (carrying or borrowing). Also, this strategy can be difficult to use for missing addend and missing subtrahend calculations, such as $189+\ldots=346 ;$ or $346-\ldots=189$ ) .

Notice that both 189 and 157 are broken up for $189+157=\ldots$

\section{Expanded notation, and mathematics drawings or manipulatives (horizontal)}

A 'break up both numbers' strategy, rearranging manipulatives or drawing quick 100 s with squares, quick 10 s tens with lines, and quick 1 s with dots, then regrouping.

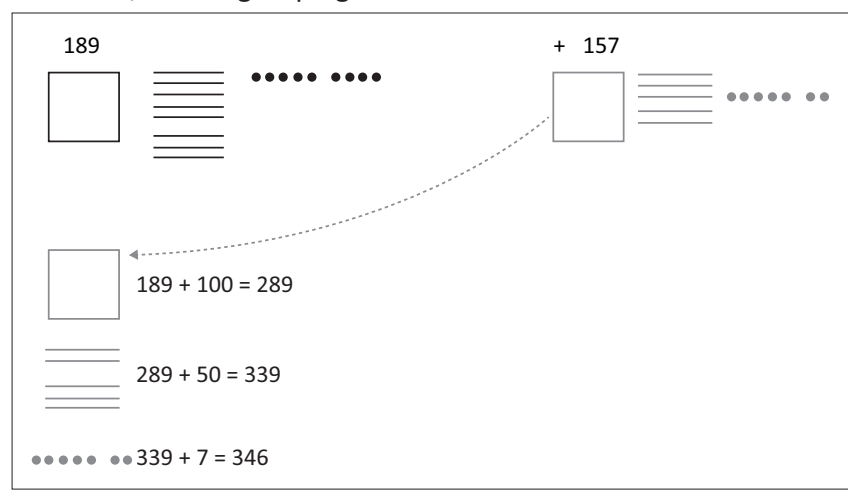




\section{Rearranging mathematics drawings or manipulatives (vertical)}

A 'break up both numbers' strategy, rearranging manipulatives or drawing quick 100s with squares, quick 10 s tens with lines, and quick 1 s with dots, then regrouping.

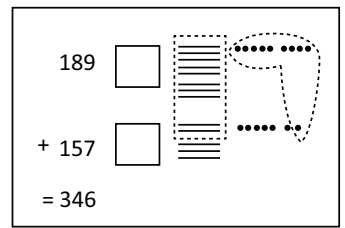

\section{Expanded notation in rows}

A 'break up both numbers' strategy, represented using rows and writing all totals (as whole numbers), then adding in columns.

$$
\begin{aligned}
189 & =100+80+9 \\
+157 & =100+50+7 \\
\hline & =200+130+16 \\
& =346
\end{aligned}
$$

\section{Write all total or partial sums in columns}

A 'break up both numbers' strategy, represented using columns and writing all totals (as whole numbers) below.

$$
\begin{array}{r}
189 \\
+157 \\
\hline 200 \\
130 \\
16 \\
\hline 346
\end{array}
$$

\section{Expanded column: Add first then exchange}

A 'break up both numbers' strategy, represented using columns, writing all totals first (in their place value column), and then exchanging one place at a time.

$$
\begin{array}{r|r|r}
\mathrm{H} & \mathrm{T} & \mathrm{O} \\
1 & 8 & 9 \\
+1 & 5 & 7 \\
\hline 2 & 13 & 16 \\
2 & 14 & 6 \\
3 & 4 & 6
\end{array}
$$

Standard written algorithm (SWA, condensed, traditional column, vertical)

A 'break up both numbers' strategy, represented using columns, exchanging using digits at the top of in place value columns and making use of digit-wise place-value ( 1 hundred 8 tens and 9 ones).

$\begin{array}{r}18^{1} 9 \\ +157 \\ \hline 346\end{array}$

